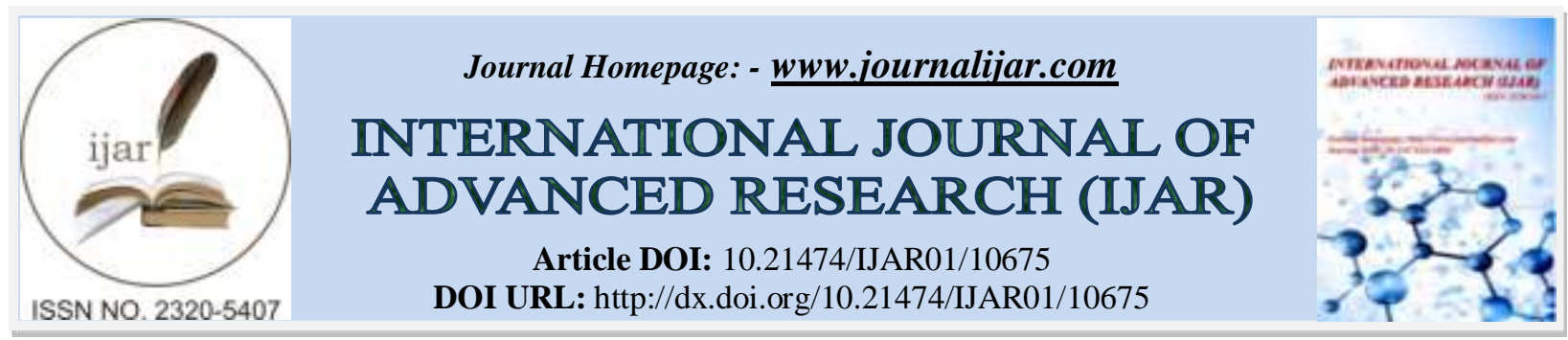

RESEARCH ARTICLE

\title{
HUMANITARIAN MISSION OF PLASTIC SURGERY SERVICE ONE YEAR EXPERIENCE FROM MILITARY HOSPITAL TO CAMP ZAATARI: ABOUT 1643 CASES
}

\author{
Ghita Belmaati Cherkaoui, Sara Lahsaini, Abdenacer Moussaoui and Mohamed amine Ennouhi \\ Reconstructive and Plastic Surgery Unit, Military Hospital of Moulay Ismail, Meknes - Morocco.
}

\section{Manuscript Info \\ Manuscript History \\ Received: 15 January 2020 \\ Final Accepted: 17 February 2020 \\ Published: March 2020 \\ Key words:- \\ Humanitarian Mission, Experience in \\ Zaatari Camp, Plastic Surgery; \\ Precarious Situation}

\begin{abstract}
Introduction: Plastic surgery in humanitarian missions, aims to help patients who are victims of war or disaster. Following the outbreak of the conflict in Syria, the health service of the Royal MoroccanArmed Forces deployed a fieldhospital in 2012 in Camp Zaatari. The objective of thisstudyis to shareourexperiencewithany plastic surgeon wishing to participate in a humanitarian mission, by shedding light on the difficultiesencountered.

Materials and Methods: This is a retrospectivestudy of the refugeeswhoweretaken care of by the Moroccanhumanitarian mission between 2012 and 2013.

Results: The seriesincludes 1643 patients, of which $81.6 \%$ wereburns, 4.9\% hadburnsequelae, $9.37 \%$ hadwounds and loss of substances and $4 \%$ consulted for otherreasons. Patients receivedappropriate care, the surgicaltreatment of whichwas a skin graft in 7 patients. Patients withlimbwounds or cephalicextremityweresutured (115 patients). Severe cases (polytrauma) wereevacuated to the Jordanianregionalhospital.

Discussion: The demand for plastic surgeryisenormousgiven the large number of burns and wounds. Our mission ischaracterized by the factthatwe practice the basics of ourspecialty in a new and painfulenvironment, by a precarious place of practice, by particular pathologies encountered and by the need to know many horizons of plastic surgery. We have therefore been obliged to orient our mission according to the needs of the environment.
\end{abstract}

Copy Right, IJAR, 2020,. All rights reserved.

\section{Introduction:-}

Humanitarianaid has always been very important, especially in the field of health. The demand for plastic surgery has been confirmed [1]. Working conditions in humanitarianaid are verydifferentfromourusual practice. It is a specific and complexexercisethatrequires a thoroughknowledge of the realities of the exercise and the field of intervention. It is, in essence, a free solidarity action for the beneficiaries.

Our plastic surgery team, withseveralexperiences and participations in humanitarian missions, has been working in Camp Zaatari, in the governorate of AL-Mafraq (north-eastern Jordan) since 2012. This operationwas part of the vastmechanism for the care of Syrianrefugees in Jordan, bringingtogether non-governmentalorganizations (NGOs) and United Nations (UN) organizations [2]. 
The aim of thisworkis to shareourexperience, to review the services provided by plastic surgeons duringthis mission, the difficulties of practicingsurgery in thiscontext in patients who are victims of war and disaster, and to show the usefulness of this type of mission to encourage plastic surgeons to participate.

\section{Materials and Methods:-}

This workis a retrospectivestudy, in whichweused consultation and patient records thatweremanagedbetweenSeptember 2012 and September 2013. For each record, the following data wereused:

1. Age

2. Sex

3. Socio-economiclevel

4. Reason for consultation

5. Type of intervention

6. Type of anaesthesia

Records not found, or incomplete, wereexcluded.

We'vecollected 1643 patients. The agerangedfrom 6 months to 65 years (meanagewas 31 years), withpredominantly male sex (sex ratio $\mathrm{M} / \mathrm{F}=1.5$ ). The consultations mainlyconcernedburns and sequelae, wounds, craniofacial trauma and bedsores. Wealsoperformedjust over 500 procedures. But apartfromsomeproceduresunder pure local anaesthesia or bandages undergeneralsedation.

\section{Results:-}

The pathologies presented in thischapter are only a preview of the workwecarried out on the mission.

The use of data from the consultation and hospitalizationregisters for plastic surgery made it possible to identify 1643 cases, soweclassified the pathologies into four main groups:burns came at the top of the list (1341 cases seen in the acute stage and 82 cases of sequelae), woundsurgery and loss of substances were the second reason for consultation (154 cases), surgery of skin tumors and soft parts (47 cases), and finallybedsores (6 cases) (Table 1).

Table 1:- Plastic surgeryactivity.

\begin{tabular}{|l|l|l|}
\hline Reason for consultation & number & Percentage \\
\hline Burn & 1341 & $81.6 \%$ \\
\hline Burns sequelae & 82 & $4.99 \%$ \\
\hline Wound and loss of substance & 154 & $9.37 \%$ \\
\hline Skin Tumor & 47 & $2.86 \%$ \\
\hline Pressure ulcers & 6 & $0.36 \%$ \\
\hline Cleftlip and palate & 5 & $0.3 \%$ \\
\hline Gynecomastia & 3 & $0.18 \%$ \\
\hline Tattooremoval & 5 & $0.3 \%$ \\
\hline
\end{tabular}

\section{The Burn:}

Theyaccount for $86.59 \%$ of patients.

From time to time, we have had to face familydramaswithsevereburnsinvolvingseveralmembers of the samefamily. The burning of plastic tents (82\% thermal burns) was the main cause. The burned area did not exceed $15 \%$ in most cases (922 patients) and the lowerlimbswere the mostaffected (359 patients) (Figure 1.2) withpredominance of 2nd degreesuperficialburns (63\%), whileonly $0.5 \%$ had 3rd degreeburns.

Given the context, the treatment of these pathologies consisted of local care, surgicaltreatment by skin graftswascarried out on 7 patients, then the patients werereferred to specialized structures in the Jordanian capital.

The sequelae of burnsweredividedbetweenflanges (61 cases) and keloidscars (21 cases).

Debridement and total skin graft( 32 cases), or Z-plastyalone (18 cases) or in combinationwithgrafts (11 cases) wereperformed. 


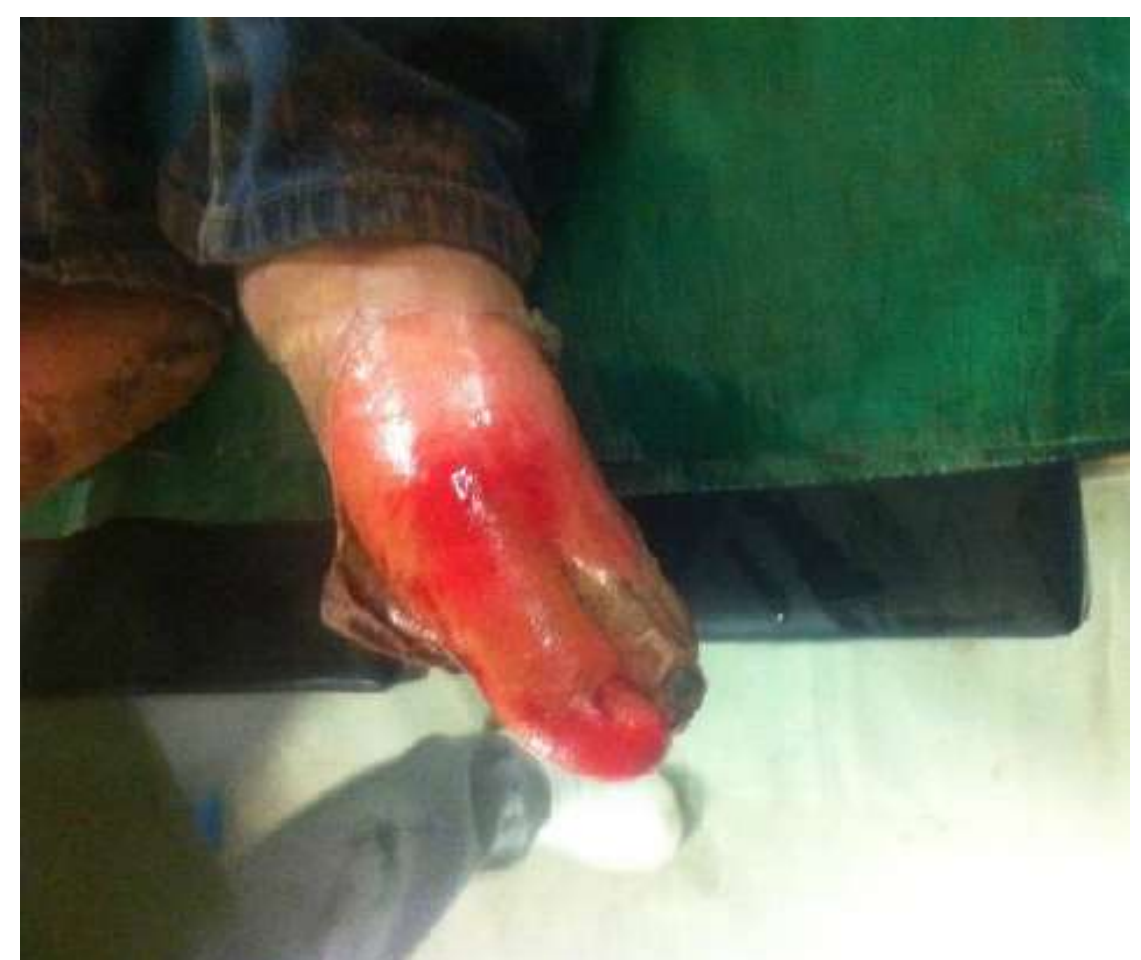

Figure 1:- Deep second-degreeburn on the left foot.

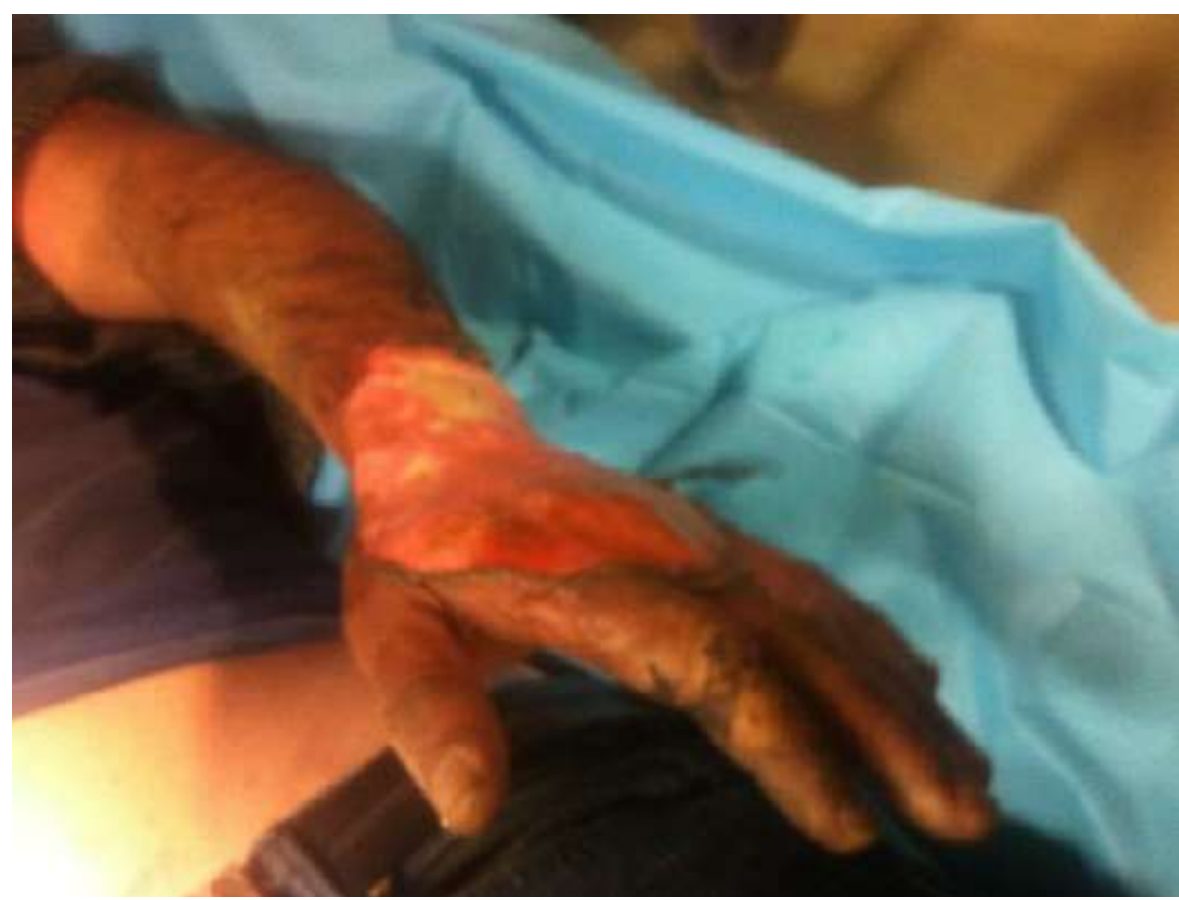

Figure 2:- Deep second-degreeburn on the left hand.

\section{Surgery for wounds and loss of substance:}

It representednearly $9.37 \%$ of ouractivity, the circumstances of occurrence are brawls and aggression (13\%). Tribal conflicts, poverty, and poorhousing conditions are the main factors at the origin of this violence. $27.2 \%$ of the woundswere due to explosions and $21.4 \%$ to ballistic trauma (Table 2). 
The cephalicextremity 56.4\% (Figure 3) and the upperlimbswere the mostaffected $20.1 \%$ (Figure 4). Treatmentconsisted of suturing (115 cases), directedwoundhealing (34 cases) and local and loco-regionalflap reconstruction (5 cases).

Table 2:- Mechanism of woundinjury and loss of substance.

\begin{tabular}{|l|l|}
\hline Mechanism & Number of cases \\
\hline Brawls & 20 \\
\hline Chute & 22 \\
\hline Explosion & 42 \\
\hline Ballistic trauma & 33 \\
\hline Gunshotwound & 6 \\
\hline Unspecified & 31 \\
\hline
\end{tabular}

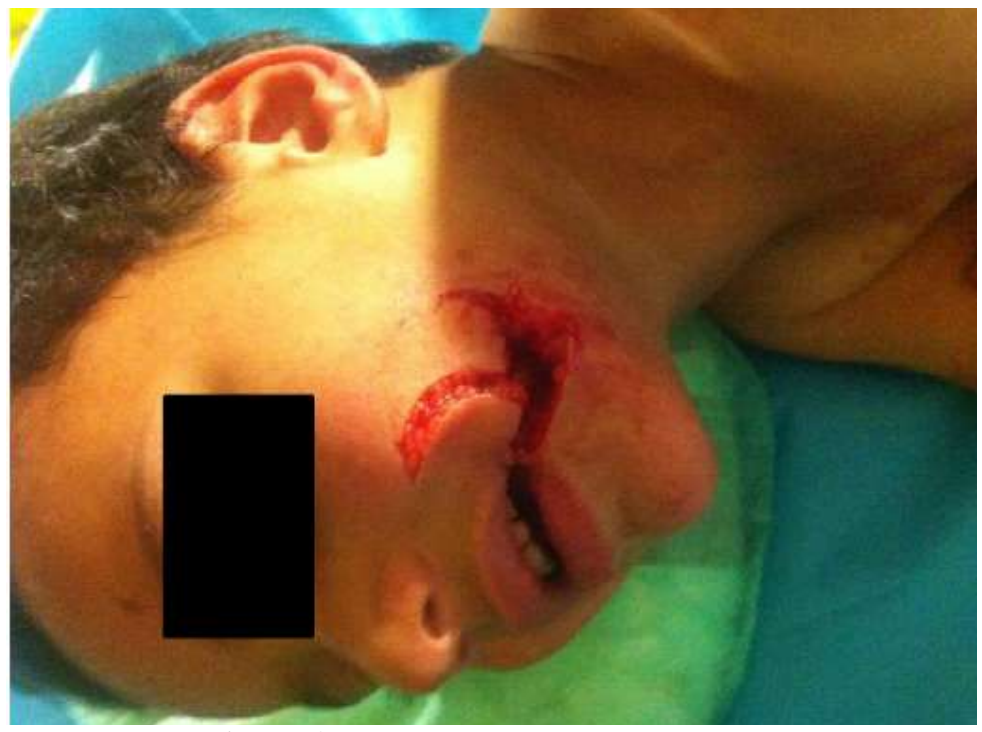

Figure 3:- Deepwound on the leftcheek.

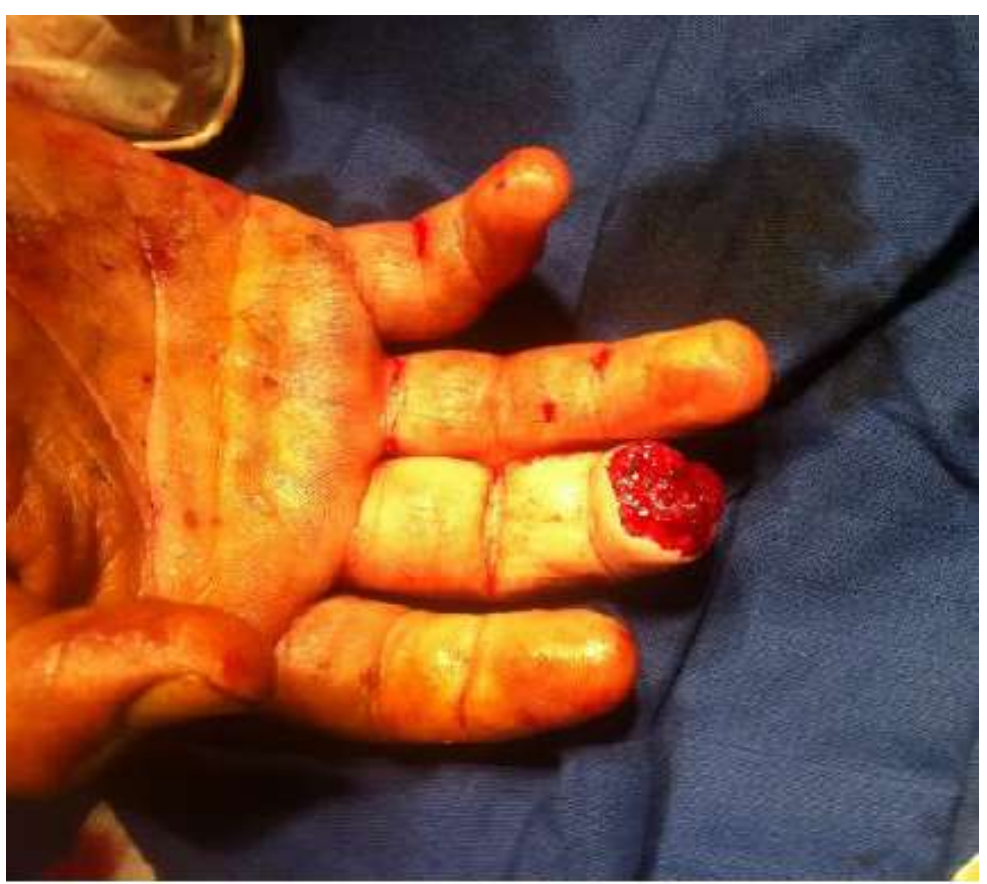

Figure 4:- Loss of substance from the fingerpulp. 


\section{Skin tumors:}

Theyaccounted for $2.86 \%$ of cases. In the majority of cases, these are benigntumours and a few malignanttumours (basal cellcarcinoma) electivelyinvolving the scalp. The treatmentwas an excision in all patients.

\section{bedsores:}

Our seriesincluded 6 patients. Most of the patients wereparaplegics. The meanagewas 29 years, withextremesrangingfrom 21 to 45 yearsold, predominantly male (sex ratio $M / F=2$ ). Three patients hadischialbedsores, two sacral bedsores and one heel sore. Theybenefitedfrom local trimming and care. The management of this type of patients revealsratheradapted, evenspecialized structures.

\section{Discussion:-}

This type of experience tends to overturneverythingwetake for granted or obvious in ourdailylives. The reflectionis about the usefulness of such a commitment for the population beingtreated;itis about the political and economicuniverse of the host country whichisoften the cause of the mission; itis about an ethicalsurgical attitude and the quality of the workdone.

\section{Plastic surgery in a precarioussituation?}

It's the practice of reconstructive surgery in difficult situations. It is more commonlycalled "humanitarian plastic surgery".

It ischaracterizedby: a new and difficultenvironment, a precarious place of practice, particular pathologies encountered, and the application of all the fields of plastic surgery (hand surgery, treatment of burns and theirsequelae, traumatologicalsequelae, maxillofacialsurgery, etc...)[3].

\section{Target population?}

Missions are offered to all patients in countries or institutions thatrequestthem. The teams try to treat patients in all fields of plastic surgery or they focus their mission on a specificpathology. The aimremains to treat patients who, in any case, wouldnever have had the opportunity to accesssuch care in their country [3].

For our mission itwas a fragile population, whichmovedfrom the southern provinces of Syria (Deraa and Homs) to the north of Jordan. Unfortunately, and as is the case in all disasters and armedconflicts, the living conditions of theserefugeesweredeplorable (promiscuity, lack of hygiene...).

\section{The drill site?}

It isoftenprecariousboth by the actual conditions of exercise (poorlyperforming operating room, frequent power cuts, etc...) and by the progress of the mission (massive influx of patients, delayed care, unprepared patients, etc...).

Our humanitarian mission took place at the Moroccanfieldhospital in the Zaatari camp, the only structure to ensure a medical permanence in the camp.

It is a hugeexpanse of tents and mobile homes, in the centre of a vastarid and stony plain in northern Jordan, a few kilometresfrom the Syrian border.

\section{The composition of the teams?}

It variesaccording to the missions. A mission caninclude a single surgeon if the structure hostingitalready has the surgicalenvironment for the operations. Conversely, a mission canbecomposed of a complete team to becompletelyautonomous[3].

For our mission, the ArmyHealth Service (SSA) was in charge of the planning and implementation of thishumanitarianoperation, determining the list of personnel supervised by the Chief MedicalOfficer. There was one plastic surgeon and one nurse experienced in plastic surgery care.

\section{Principle of care ?}

In precarious situations, the practice of plastic surgery must respect certain principles. Knipper has groupedthemtogetherunder the name "4F concept": [3]

F for Feasibility: an operation must befeasibleunderprecarious conditions and by a single surgeon. 
F for Fiability: a technique must bereliable. Failureisbadlyexperienced, especially by the professional and family entourage.

F for Familiarity: the procedure must befamiliar to the operator. It is best appliedwhen the situation isdifficult.

F for Facility: a technique must remaineasy to teach: Cooperativework $=$ Transmission of information.

The surgical techniques used in our mission (grafts, local plasty...), seemed to us to respond to this concept. Weadvisedifferenttherapeuticproposals, from the "simple" to the "complicated":therapeutic abstention, directedhealing, skin graft, flap.

\section{Conclusion:-}

The necessity of the missions seems to have been taken for granted by most of us today. The demand for plastic surgeryisenormousgiven the large number of burns and wounds. This surgicaladventure has changed the waywework. In order to shareourexperience, we have tried to focus on the different pathologies observed in ourstudy and the therapeutic attitudes used to treatthesewarvictims. If a surgeon wants to participate in a plastic surgery mission, he must becompletelyautonomous and know the basic techniques, namely: skin plasties and skin grafts.

\section{Conflict of Interest:}

The authorsdeclarethatthey have no conflict of interest.

\section{References:-}

1. P. Knipper, P. Antoine, C. Carré, J. Baudet. Chirurgie plastique nomade: 1 ONG, 10 années, 30 missions. Annal ChirurgiePlastiqueEsthétique (2015) .03.003

2. N.Mocellin, E. Hornez, X. Bajard, S.Legoudeveze, C.Charpail, D.Ollat. Action humanitaire et Service de Santé des Armées : Expérience d'une antenne chirurgicale en Jordanie sur la frontière syrienne. e-mémoires de l'Académie Nationale de Chirurgie, 2014, 13 (2) : 028-033

3. P.Knipper. Chirurgie plastique en situation précaire.25, rue de Bourgogne - 75007 Paris Hôpital Saint Antoine 75012 Paris. 